\title{
Polen Taşıyan Bal Arılarının MobileNetV2 Mimarisi ile Sinıflandırılması
}

\author{
Yusuf Yarg1 Baydilli ${ }^{1 *}$ \\ ${ }^{1}$ Hakkari Üniversitesi, Mühendislik Fakültesi, Bilgisayar Mühendisliği Bölümü, İstanbul, Türkiye (ORCID: 0000-0002-4457-2081)
}

(İlk Geliş Tarihi 7 Aralık 2020 ve Kabul Tarihi 31 Ocak 2021)

(DOI: 10.31590/ejosat.836856)

ATIF/REFERENCE: Baydilli, Y.Y. (2021). Polen Taşıyan Bal Arılarının MobileNetV2 Mimarisi ile Sınıflandırılması. Avrupa Bilim ve Teknoloji Dergisi, (21), 527-533.

$\ddot{O} \mathbf{z}$

Bal arıları çiçeklerden topladıkları polenlerin bir kısmını kovanlarına taşıyarak kovanın enerji ihtiyacını karşılamaya çalışırlar. Bu nedenle, kovana giren bal arılarından polen taşıyanların tespit edilmesi, kovanın sağlığı hakkında iyi bir indikatör olarak görev yapmaktadır. Bu çalışmada, polen taşıyan bal arılarının doğru bir şekilde sınıflandırılmasına yönelik bir çözüm geliştirmek amacıyla, bal arıları görüntüleri kullanılarak bir MobileNetV2 derin öğrenme mimarisi eğitilmiştir. Veriye göre seçilen doğru eğitim stratejisinin sonuçlara yaptığı katkı sorgulanmış, ince ayar yöntemi ile eğitilen modelin test verisi üzerindeki başarı oranı $\% 99,00$ olarak ölçülmüştür. Çalışma sonunda, arı çiftçilerinin mobil cihazlar ile arı kovanının genel durumu hakkında başarılı bir şekilde yorum yapabileceği gösterilmiştir.

Anahtar Kelimeler: Polen taşıyan bal arıları, derin öğrenme, transfer öğrenme, ince ayar, sınıflandırma.

\section{Classification of Pollen-Bearing Honey Bees using MobileNetV2 Architecture}

\begin{abstract}
Honey bees try to meet the energy needs of the hive by carrying some of the pollen they collect from flowers to their hive. Therefore, identifying those pollen-bearing honey bees entering the hive serves as a good indicator of the health of the hive. In this study, a MobileNetV2 deep learning architecture was trained using images of honey bees to develop a solution to quickly and accurately classify pollen-bearing honey bees. The contribution of the correct training strategy selected according to the data to the results was questioned, and the success rate of the model trained with the fine-tuning method on the test data was measured as $99.00 \%$. At the end of the study, it was shown that bee farmers can quickly and successfully comment on the general condition of the bee hive using mobile devices.
\end{abstract}

Keywords: Pollen-bearing honey bees, deep learning, transfer learning, fine-tuning, classification.

\footnotetext{
* Sorumlu Yazar: Hakkari Üniversitesi, Mühendislik Fakültesi, Bilgisayar Mühendisliği Bölümü, İstanbul, Türkiye (ORCID: 0000-0002-4457-2081), yusufbaydilli@hakkari.edu.tr
} 


\section{Giriş}

“Arllar dünya üzerinden kaybolurlarsa, insanlı̆̆ın sadece dört yıllık ömrü kalır. Arı olmazsa, tozlaşma olmaz, bitki olmaz, hayvan olmaz, insanlık olmaz." Bu cümlelerin Albert Einstein tarafından, arıların insanlık için sahip olduğu önemi anlatmak için dile getirildiğine inanılmaktadır (Schönfelder \& Bogner, 2017). Çünkü arılar ekosistem içerisinde oldukça önemli bir göreve sahiptir: polinasyon (tozlaşma) (Silici, 2020). Bal arıları kış aylarında hayatta kalabilmek amacıyla bal üretirler (Tüzün \& Bilgili, 2013). Bal üretiminin ilk aşaması da çiçeklerden nektar toplanmasıdır (Sarıgül, 2018). Bu işlem sırasında çiçeklerin erkek organlarından arıların çeşitli uzuvlarına bulaşan polenler, çiçeklerin dişi organlarına temas etmesi sonucu döllenme adı verilen işlem gerçekleşmiş olur (Sıralı et al., 2011). Bu süreç sayesinde de tohumların etrafa saçılarak bitkilerin çoğalması sağlanır. Aynı zamanda bitkilerin çiçek açmasına, meyve ve sebze üretimine doğrudan katkı sağlanır (Türkiye Arı Yetiştiricileri Merkez Birliği, 2016b). Arılar polinasyon sürecinin yaklaşık \%80’ninden sorumludurlar (Bağrıaçık, 2017).

Polinasyon işleminin dışında, bu küçük mucizevi yaratıklar, arı mumu (kozmetik), polen (gıda), propolis (tıp) ve arı sütü (ilaç endüstrisi) gibi farklı sektörlerde aktif olarak kullanılan oldukça faydalı ürünleri de üretmektedirler (Silici, 2014). Diğer yandan, arıların nektar arayışı sürecindeki davranışları Yapay Arı Kolonisi algoritmasına da ilham kaynağı olmuştur (Karaboga \& Basturk, 2007).

Bal arıları vücudunda kalan polenlerin bir kısmını nektar ile zenginleştirerek arka bacaklarında yer alan polen sepetinde biriktirirler ve kovanlarına taşırlar (Başdoğan et al., 2019). Üretilen polenler kovandaki arılar için enerji kaynağı olarak kullanılarak yavru gelişimini mümkün kılar (Türkiye Ar1 Yetiştiricileri Merkez Birliği, 2016a). Aynı zamanda polenler insanoğlu için oldukça zengin protein ve vitamin kaynağ olduğundan, arı çiftçileri tarafından kovan girişine kurulan tuzaklar yardımıyla toplanmaktadır (Ankara Valiliği Gıda Tarım ve Hayvancilık İl Müdürlüğü, 2015; Bozkurt, 2020). Bu nedenlerden dolayı, kovana giren arılardan polen taşıyanların sayısı, yoğunluğu gibi nicelikler, arı çiftçilerinin hem kovanların genel sağlık durumu hem de kovanın rekoltesi hakkında yorum yapabilmelerine imkân sağlamaktadır (Babic et al., 2016).

Literatürü incelediğimizde, bal arılarının kovana giriş-çıkış sürecindeki davranışlarının veya sayılarının görsel sistemler aracılığıyla incelenmesine yönelik çalışmalar gözlemlemek mümkünüdür (Chen et al., 2012; Tu et al., 2016). Fakat, polen taşıyan arıların bilgisayarlı görü modelleriyle tespiti konusundaki çalışma sayısı oldukça azdır. Babic vd. (Babic et al., 2016) 2016 yılında gerçekleştirdikleri çalışmada Rasperry Pi kartına takılan bir kamera aracılığıyla görüntüler almışlardır. Oluşturdukları veri setinde yer alan arıların segmentasyonu sürecinde Gauss Karışım Modeli modeli kullanan araştırmacılar, çıkarımını yaptıkları özellikleri en yakın ortalama algoritması ile sınıflandırmışlardır. Çalışma sonunda \%88,70 doğruluk oranına ulaşmışlardır. Bir diğer çalışma da ise, Rodriguez vd. (Ivan F. Rodriguez et al., 2018) kamera yardımıyla kaydettikleri video görüntülerinden, polen taşıyan ve taşımayan arıları içeren kesitler alarak bir veri seti oluşturmuşlardır. Sınıflandırma aşamasında hem klasik hem de derin makine öğrenme modellerini içeren testler gerçekleştirerek en yüksek performansa ulaşmaya çalışmışlardır. Çalışma sonunda, derin transfer öğrenme yöntemlerinin yeterince başarı gösteremediğini ve en yüksek başarının en-baştan eğitilen bir Konvolüsyonel Sinir Ağları (CNN) modeli ile elde edildiğini rapor etmişlerdir $(\% 96,40)$.

En-baştan CNN eğitimi stratejisi birçok problemde başarılı olabilse de kurulacak mimaride yer alan hiper-parametrelerin doğru optimizasyonu hala zor bir süreçtir (Feurer \& Hutter, 2019). Aynı zamanda en-baştan eğitim stratejisi için oldukça fazla veri ihtiyacı bulunmaktadır (Shen et al., 2017). Fakat, literatüre yeni kazandırılan tekniklerle zenginleştirilen, aynı zamanda, hiperparametre optimizasyonuna da ihtiyaç duymayan derin mimarilerin, transfer öğrenme veya ince ayar stratejisi ile eğitilmesi sayesinde, yüksek başarı oranlarına daha hızlı ve kesin bir şekilde ulaşmak mümkün olabilmektedir (Hendrycks et al., 2019). Diğer yandan, arı çiftçilerinin kovan girişine kurulacak yüksek maliyetli kayıt cihazları yerine mobil cihazlar ile arı kovanlarının genel durumu hakkında bilgi sahibi olmalarının da önü açılmalıdır. Dolayısıyla bu çalışmada, ince ayar eğitim yöntemi kullanılarak polen taşıyan arılarının yüksek doğrulukla sınıflandırılmasına yönelik bir çalışma gerçekleştirilmiştir. Eğitim modeli olarak işlem maliyeti açısından hafif ve mobil uygulamalara da uygun olan MobileNetV2 mimarisi tercih edilmiştir. Çalışma sonunda doğru eğitim stratejisi ile literatürdeki diğer çalışmalara nazaran daha yüksek başarı oranlarına ulaşılabilmiştir.

Makalenin geri kalanı şu şekildedir: İkinci bölümde veri seti tanıtılmış, üçüncü bölümde ise çalışmada kullanılan model gösterilmiştir. Dördüncü bölüm elde edilen deneysel sonuçları ve tartışma bölümünü içermektedir. Son bölümde ise çalışmanın sonunda elde edilen genel kazanımlar verilmiştir.

\section{Veri Seti}

Çalışmamızda Rodriguez vd. tarafından oluşturulan veri seti kullanılmıştır (Ivan F. Rodriguez et al., 2018; Ivan Felipe Rodriguez, 2018). Veri setinin oluşturulması aşamasında yazarlar kovan girişine bir rampa yerleştirmişler ve bu rampayı 4 Mega piksel çözünürlüğe sahip bir kamera ile kaydetmişlerdir. Elde ettikleri birer saatlik video kayıtlarından, el yordamıyla, polen taşıyan ve taşımayan bal arılarını barındıran kesitler almışlardır. Her bir kesit sadece bir bal arısı içermektedir. Toplam 700 görüntüden oluşan veri setinin yaklaşık \%15'i test verisi olarak ayrılmıştır. Veri setinin genel özellikleri ise Tablo 1'de görülebilir.

Derin öğrenme yöntemlerinin başarısı eğitimde işlediği veri sayısı ile doğru orantılıdır. Diğer bir deyişle, bir derin öğrenme modeli eğitim sırasında ne kadar farklı varyasyonda veri ile karşılaşırsa, test örnekleri üzerinde o kadar fazla genelleştirme yeteneğine sahip olur. Ne yazık ki, çoğu zaman, yeterince geniş veri seti oluşturmak mümkün olmamaktadır. Bu gibi durumlarda, modele genelleştirme yeteneği kazandırmak için veri arttırma tekniklerinden faydalanılır (Perez \& Wang, 2017).

Bir diğer problem de veri setinin özelliklerine göre doğru veri arttırma tekniklerinin belirlenmesidir. Yanlış seçilen teknik sınıflandırmaya katkı sunmaktan ziyade başarı oranlarının önemli ölçü de azalmasına veya sınıflandırıcı modelin verinin farklı özelliklerine odaklanmasına yola açabilmektedir. Bu da negatif transfer denen fenomenin ortaya çıkmasına neden olur (Cubuk et al., 2018). 
Tablo 1. Veri setinin genel özellikleri.

\begin{tabular}{ccc}
\hline Bal arısı veri seti & Polen taşıyan & Polen taşımayan \\
\hline & & \\
Örnek görüntü & \multicolumn{2}{c}{3} \\
Renk kanalı sayısı & $380 \times 300$ \\
Çözünürlük & 354 & 346 \\
Örnek Sayısı & 300 & 300 \\
Ĕgitim seti & 54 & 46 \\
Test seti &
\end{tabular}

$\mathrm{Bu}$ sebeple gerek eğitim gerek test verileri incelendikten sonra, verilerde yer alan değişikliklerin genellikle görüntülerin afin transformasyon özelliklerinde gerçekleştirildiği gözlemlenmiştir. Dolayısıyla, $x$-ekseninde çevirme (horizontal flip), $x$-ekseninde yer değiştirme (translate-x), y-ekseninde yer değiştirme (translate-y), döndürme (rotate), makaslama (shear) gibi teknikler kullanılarak eğitim veri seti 3 katına çıkarılmış ve toplam 1.800 görüntü ile eğitim sürecine geçilmiştir.

\section{Model}

Derin öğrenmenin son on yllda bu denli popülerleşmesinin belki de en önemli nedeni yar1-iletken ve transistör teknolojisindeki gelişmelerdir (Shen et al., 2017). Bu gelişmeler sayesinde, yüksek boyutlardaki veri setlerini hızlı bir şekilde işleyen güçlü işlemci birimlerine daha az maliyetle ulaşmak mümkün olmuştur. Fakat, veri sayısı arttıkça ve problem zorlaştıça, aynı oranda derin öğrenme modelleri de karmaşıklaşmaktadır. Eğitilecek parametre sayısı yüz milyonlar seviyesine çıkmakta, başarı artsa da hız konusunda tatminkâr sonuçlar elde edilememektedir. Bu nedenle araştırmacılar da daha az eğitim parametresine sahip, küçük ama verimli derin öğrenme mimarileri oluşturmaya yönelmişlerdir. MobileNet (Howard et al., 2017) mimarisi de bu kaygıları göz önünde bulundurarak, bilgisayarlara nazaran daha düşük veri işleme yeteneğine sahip mobil ve gömülü sistemlerde derin öğrenme uygulamaları geliştirilebilmesini hedeflemiştir.

MobileNet mimarisi görüntülerden konvolüsyonel filtrelerle özellik çıkarımı aşamasında, standart konvolüsyonel operasyonu yerine daha önce Xception (Chollet, 2017) mimarisinde de karşımıza çıkan Derinlemesine Ayrllabilir Konvolüsyon (Depthwise Separable Convolutions) tekniğini kullanmaktadır. $\mathrm{Bu}$ teknik sayesinde standart konvolüsyon işlemine nazaran sekiz veya dokuz kat daha az parametreyle özellik çıarımı yapilabilmektedir.

2019 yılında ise MobileNet mimarisi geliştirilerek, daha hızlı ve daha verimli olacak şekilde güncellemeler yapılmıştır. $1 x 1$ konvolüsyonlar kullanılarak özellik haritalarının boyutu daraltılmıştır. Ayrıca, ResNET (Szegedy et al., 2017) modellerinde de yer alan bağlantı atlama (skip connection) tekniği sayesinde daha hızlı bir hesaplama süreci sağlanmıştır. MobileNetV2 (Sandler et al., 2019) mimarisi kullanılarak ImageNet veri seti üzerinde gerçekleştirilen testlerde, kendisinden çok daha fazla parametreye sahip derin mimarilere oldukça yakın performans gösterdiği saptanmıştır (Keras, 2020).
Örneğin, yaklaşık 143,5 Milyon parametreye sahip olan VGG19 mimarisinin ulaştığı başarı oranına sadece 3,5 Milyon parametreyle ulaşabilmiştir.

\section{Deneysel Sonuçlar ve Tartışma}

Transfer öğrenme, başka bir problemde öğrenilen bilgilerin yeni bir problemde kullanılması olarak tanımlanır ( $\mathrm{Lu}$ et al., 2015). Bu sayede yeni problemin daha hızlı ve başarılı bir şekilde çözülmesi mümkün olmaktadır. Derin öğrenme mimarilerinin ilk katmanlarının görüntünün genel özelliklerinin çıkarımını yapması, sonraki katmanların ise daha spesifik özelliklere odaklanması sayesinde, bir görevden kazanılan yeteneklerin başka görevlere transfer edilebilmesi mümkün olmaktadır (Hendrycks et al., 2019). Bu modeller kullanılarak bilgi transferi yapılacak veri seti üzerinde hangi eğitim stratejisinin kullanılacağına ise genellikle iki değişken üzerinden karar verilir: veri seti boyutu ve benzerlik.

ImageNET (ImageNet, 2020) veri seti derin öğrenme modellerinin test aşamasında kullanılmak üzere geliştirilmiş oldukça popüler bir veri setidir. Bünyesinde 14 Milyondan fazla görüntü barındırmaktadır. Ayrıca, 20.000'den fazla kategoriye sahiptir. Verilerin sınıfları bitki, hayvan, doğa, insan vs. gibi geniş bir skalada yer almaktadır. Bu nedenle, bilgisayarlı görü alanında çalışan araştırmacıların inşa ettiği modellerin genelleştirme yeteneği bu veri seti kullanılarak ölçülmektedir. Dolayısıyla, ImageNET kullanılarak eğitilen modellerin kaydedilen ağırlık değerleri, yeni veri setleri için iyi bir özellik çıkarıcı olma özelliğine de sahiptir.

$\mathrm{Bu}$ veri seti aynı zamanda "bal arısı" görüntüleri de içermektedir. O zaman, polen taşıyan bal arılarının tespitinde kullanılacak veri setinin, MobileNetV2 modelinin ilk ağırlıklandırılmasında kullanılan ImageNET veri setine çok benzer olduğu söylenebilir. Veri setinin boyutu (600) ise derin öğrenme modelleri için yetersiz sayıdadır. Bu sebeple, model üzerinde yapılacak bir ince ayar sürecinin ezberlemeye neden olacağı, bunun yerine transfer öğrenme (modelin özellik çıkarıcı olarak kullanılarak, sadece modelin son bölümünde yer alan sinıflandırıcı bölümünün eğitilmesi) önerilmektedir (Karpathy, 2018). Fakat, hem veri arttırımı sayesinde daha fazla örnek oluşturulduğundan, hem de MobileNetV2 mimarisinin ilk katmanlarında diğer derin öğrenme mimarilerine nazaran daha az parametre olduğundan ince ayar eğitim stratejisi de seçenek olarak karşımıza çıkmaktadır (Yosinski et al., 2014). Bu sayede, modelin tamamının veya bir bölümünün eğitime dahil edilerek ve hesaplanan hatanın katmanlara yayılması sağlanarak, modelin yeni verilere adapte olması sağlanabilecektir.

\subsection{Deneysel Sonuçlar}

Veri setinin eğitimi sürecinde iki yöntem de kullanılarak karşılaştırmalı bir analiz gerçekleştirilmiştir. Modeller 50 devir için eğitilmiştir. Eğitim verisi üzerinde 10-katlı çapraz doğrulama (10-fold cross-validation) tekniği kullanılarak modelin kendini en iyi şekilde geliştirebildiği ve kararlı hale getirebildiği eğitimdoğrulama verilerinin seçimi sağlanmıştır. 10 eğitim sonunda, bağımsız test verisi üzerinde en iyi performans gösteren modeller ile değerlendirme aşamasına geçilmiştir.

İnce ayar sürecinde MobileNetV2 modelinin sahip olduğu 154 katman da eğitime dahil edilmiştir. Son konvolüsyonel katmanı Global Ortalama Havuzlama (Global Average Pooling) 


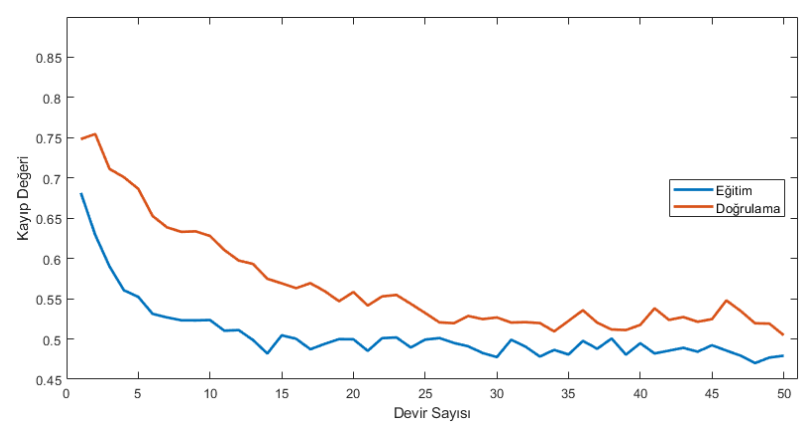

a) Transfer öğrenme kayıp değerleri

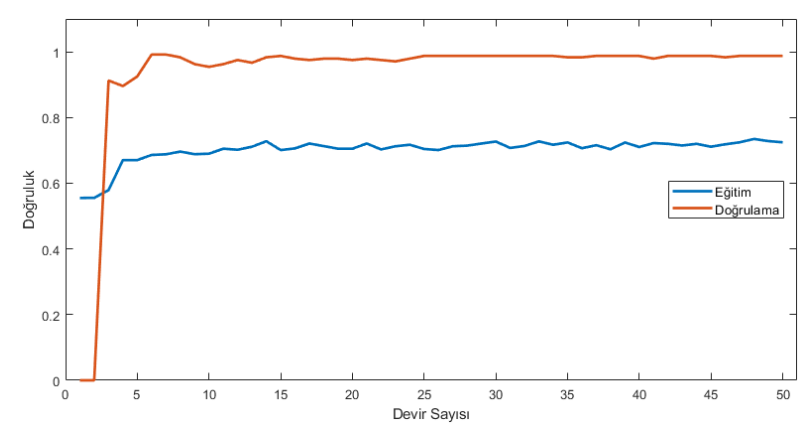

c) Transfer öğrenme doğrulama değerleri

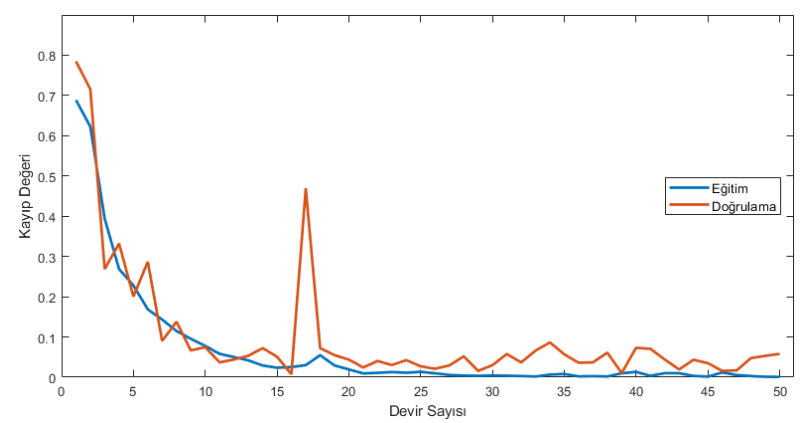

b) İnce ayar kayıp değerleri

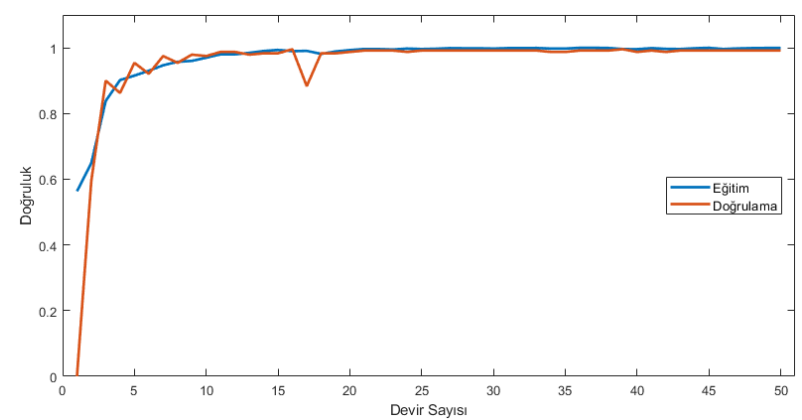

d) İnce ayar doğrulama değerleri

Şekil 1. Ĕgitim sonunda elde edilen eğitim-doğrulama ĕgrileri.

ile düzleştirilmiş ve sırasıyla 256 ve 64 nörona bağlanmıştır. Son katmanda ise sınıf sayısı kadar (2) çıkış nöronu yer almaktadır. Eğitim sırasında $A D A M$ optimizasyon algoritması kullanılmıştır. Ezberlemenin önüne geçmek adına öğrenme oranı oldukça düşük tutulmuştur $\left(1 \times 10^{-5}\right)$. Yaklaşık 2,5 Milyon parametre ile modelin eğitilmesi sağlanmıştır.

Transfer öğrenme ile gerçekleştirilen eğitim sonunda, Şekil 1.a'da görüldüğü üzere, eğitim kayıp değerlerinin ilk devirlerden itibaren 0,47 seviyesinde kaldığı ve kendini daha fazla iyileştiremediği görülmüştür. İnce ayar sürecinde ise eğitim kayıp değerleri O'a oldukça yaklaşmıştır (Şekil 1.b). Doğrulama değerleri incelendiğinde ise, transfer öğrenme sürecinde eğitim doğruluğunun düşük değerlerde kalırken, ilginç bir şekilde doğrulama verisi üzerinde modelin oldukça yüksek doğruluk değerlerine ulaştığı görülmüştür (Şekil 1.c).

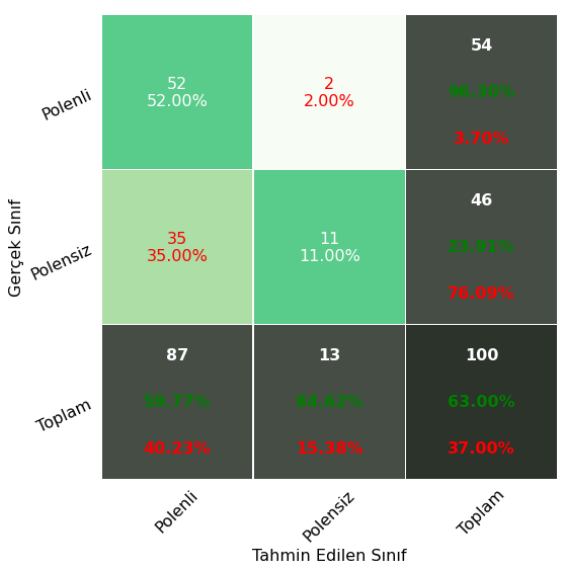

a) Transfer öğrenme
İnce ayar sürecinde ise model kararlı davranmış ve hem eğitim verisi üzerinde hem de doğrulama verisi üzerinde yüksek başarılar elde etmiştir (Şekil 1.d). Özetle, transfer öğrenme sürecinin net bir şekilde öğrenememe (underfitting) probleminden muzdarip olduğu görülmüştür. Sonraki aşamada eğitilen iki model ile test verisi üzerinde tahmin gerçekleştirilmiştir. Elde edilen sonuçlar Şekil 2'de görülebilir.

Beklendiği üzere transfer öğrenmeyle eğitilen model, Rodriguez vd. (Ivan F. Rodriguez et al., 2018)'nin çalışmalarındaki sonuçlara benzer bir şekilde, oldukça düşük başarı oranları üretmiştir. İnce ayar ile eğitilen MobileNetV2 modeli ise sınıflar arasında ayrım sağlayan özellikleri (polen topları) net bir şekilde tespit edebilmiş ve \%99 gibi oldukça yüksek bir doğruluk değerine ulaşmıştır.

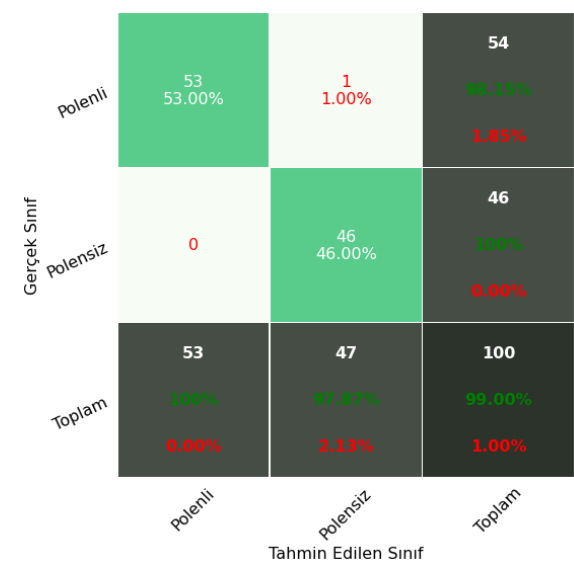

b) İnce ayar

Şekil 2. Hesaplanan karmaşıklık matrisleri. 


\subsection{Tartışma}

Grad-CAM yöntemi konvolüsyonel mimarilerinin tahmin gerçekleştirirken görüntünün hangi bölümüyle ilgilendiğini incelemek amaciyla kullanılmaktadır. $\mathrm{Bu}$ yöntemde, son konvolüsyonel katmanının sahip olduğu değerler Global Ortalama ile düzleştirilerek tahmin gerçekleştirilir. Son katmandaki özellik haritalarının türevlenebilir olması sayesinde bir 1S1 haritası oluşturularak, modelin yoğunlaştığı bölgeler incelenebilmektedir.

Çalışmanın bu aşamasında, transfer öğrenme yönteminin "polen taşıyan bal arıları" veri seti üzerinde neden başarısız olduğunu daha net tartışmak adına Grad-CAM (Gradientweighted Class Activation Mapping) (Selvaraju et al., 2017) yöntemi kullanılarak MobileNetV2 mimarisinin veri setinde yer alan örneklerin hangi özelliklerine odaklandığı incelenmiştir (Şekil 3).

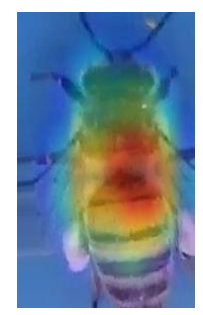

a) Polen taşıyan

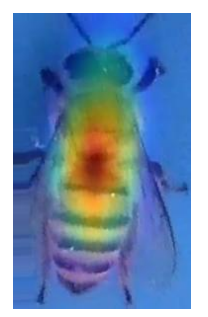

b) Polen taşımayan
Şekil 3. Polen taşıyan ve taşımayan arıların Grad-CAM analizi (kırmızı bölümlerin aktivasyon değerleri daha yüksektir).

ImageNET veri seti ile ağırlıklandırılmış MobileNetV2 modeli iki görüntüyü de "arı" olarak tahmin etmiştir. Isı haritasına bakıldığında ise, modelin arıların orta bölümüne odaklandı ̆̆ı net olarak görülmektedir. Dolayısıyla, model özellik çıkarıcı kullanıldığında, çıkarılan özellikler arıların temel özelliklerini içerdiğinden sınıflandırıcı model tam bir öğrenme sağlayamamıştır. İnce ayar ile eğitilen modelin ise arıların arka bacaklarında yer alan polen toplarına yöneldiği, bu sayede yüksek performans sağladığı anlaşılmaktadır (Şekil 4).

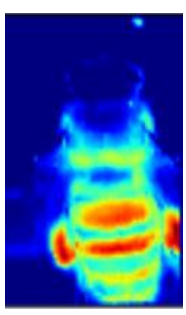

a) Polen taşıyan

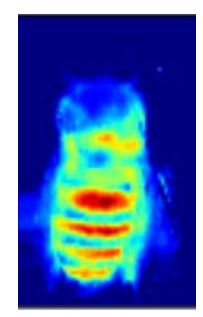

b) Polen taşımayan
Şekil 4. Ince ayar ile ĕgitilen modelin ürettiği aktivasyon haritaları (kırmızı bölümlerin aktivasyon değerleri daha yüksektir).

İnce ayar ile eğitilen model yalnızca bir örnek üzerinde başarısız olmuştur. İlgili örnek ve aktivasyon haritası Şekil 5'deki gibidir. Şekilde de net bir şekilde görüldüğü gibi, bu örnekte yer alan polen taşıyan bal arısının sahip olduğu polen topları, diğer örneklerdekine nazaran hem boyut olarak daha küçüktür hem de renk bakımından arının gövdesiyle uyumludur. $\mathrm{Bu}$ nedenle sınıflandırıcı modelin polen toplarını tam olarak ayrıştıramadığı tahmin edilmektedir.
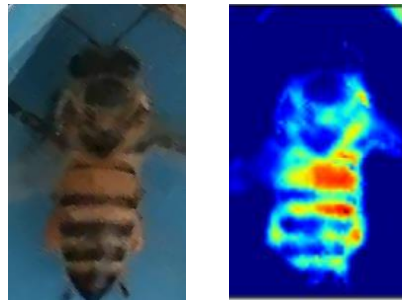

Şekil 5. Ince ayar ile eğitilen model tarafindan yanlış sınıflandırllan örnek ve örneğe ait aktivasyon haritası (kırmızı bölümlerin aktivasyon değerleri daha yüksektir).

Son olarak, çalışmamızdan elde edilen sonuçlar literatürde yer alan ve aynı veri setini kullanan çalışma ile karşılaştırılmıştır (Tablo 2).

Tablo 2. Sonuçların literatürle kıyaslanması.

\begin{tabular}{|c|c|c|c|c|}
\hline Çalış̧ma & Yöntem & Duyarlılık (\%) & Özgüllük (\%) & Doğruluk (\%) \\
\hline \multirow{5}{*}{$\begin{array}{c}\text { Rodriguez } v d . \\
\text { (Ivan F. Rodriguez et al., 2018) }\end{array}$} & $\mathrm{PCA}+\mathrm{SVM}$ & - & - & 91,16 \\
\hline & $\mathrm{CNN}$ & - & - & 96,40 \\
\hline & VGG16 & - & - & 87,20 \\
\hline & VGG19 & - & - & 90,20 \\
\hline & ResNET50 & - & - & 61,70 \\
\hline \multirow{3}{*}{ Bu çalışma } & MobileNetV2 (TÖ) & 59,77 & 84,62 & 63,00 \\
\hline & MobileNetV2 (İA) (orijinal veri seti) & 95,92 & 86,27 & 91,00 \\
\hline & $\begin{array}{l}\text { MobileNetV2 (İA) } \\
\text { (veri arttırımı) }\end{array}$ & 100 & 97,87 & 99,00 \\
\hline
\end{tabular}

Rodriguez vd. (Ivan F. Rodriguez et al., 2018) gerçekleştirdikleri çalışmada, oluşturdukları veri setini hem klasik makine öğrenme süreciyle hem de derin öğrenme süreciyle e-ISSN: 2148-2683 eğitmişlerdir. Klasik süreçte görüntülere Gauss filtreler uygulayarak özellik çıkarımı yapmışlar, daha sonra Temel Bileşenler Analizi (PCA) yöntemiyle boyut azaltma 
gerçekleştirmişlerdir. Elde edilen özellik vektörleriyle Destek Vektör Makinesi (SVM) eğitilmiştir. Derin öğrenme sürecinde ise, iki katmanlı bir CNN eğiten araştırmacılar ise \%96,40 başarı oranına ulaşmışlardır. VGG16, VGG19 ve ResNET50 mimarilerini transfer öğrenme yöntemiyle eğiten yazarlar istenilen başarı oranlarına ulaşılamadığını belirtmişlerdir.

Bu çalışmada ise, mevcut veri setinin ImageNET veri setine oldukça yakın olmasından ortaya çıkan olumsuzluk ince ayar eğitim süreci ile aşılmıştır. Sınıflandırma aşamasında ise MobileNetV2 modeli tercih edilmiştir. Bu mimari derin öğrenme teknolojisine sahip olduğundan ön-işleme (özellik çıkarımı, boyut azaltma vs.) sürecine ihtiyaç duymadan, mobil ve gömülü sistemlerde verimli bir şekilde çalışması için tasarlandığından ise hızlı ve başarılı bir şekilde sonuca ulaşılabilmiştir. Veri arttırımı uygulamadan orijinal veri seti üzerinde yapılan eğitim sonrasında modelin test verisi üzerinde ulaştı̆̆ 1 doğruluk değeri $\% 91,00$ olarak ölçülmüştür. Veri arttırımının ise sınıflandırmaya $\% 9$ oranında katkı sunduğu görülmüştür. Veri arttırımı ile genişletilen veri seti ile eğitilen model $\% 99,00$ başarıya ulaşmıştır.

\section{Sonuç}

Bal arıları, bal üretimi için ihtiyaç duyduğu nektarı çiçeklerden toplarken üzerlerinde biriken polenlerin bir kısmını kovanlarına taşırlar. Çünkü polenler, sadece bitkilerin değil, bal arılarının da devamlılı̆̆ını korumalarında önemli bir role sahiptir. Aynı zamanda insanoğlu için sağlıklı bir gıda takviyesidir. Bu nedenlerden dolayı, kovanlardaki polen seviyesi hem kovanların genel sağlık durumunu açısından hem de elde edilecek ürün miktarı açısından arı çiftçilerine önemli ipuçları sağlamaktadır.

Bu çalışmada, polen taşıyan bal arılarının yüksek başarı ile tespit edilmesine yönelik bir çalışma gerçekleştirilmiştir. Arı çiftçilerinin maliyetli bir sistem yerine mobil sistemler ile sonuca ulaşabilmesi adına MobileNetV2 modeli tercih edilmiştir. Çalışma sırasında farklı eğitim stratejileri analiz edilmiş ve mevcut veri seti üzerinde oluşan dramatik farklılıkların sebepleri tartışılmıştır. Sonuç olarak, ince ayar ile eğitilen modelin transfer öğrenmeye göre daha başarılı sonuçlar ürettiği görülmüştür $(\% 99,00)$. Gelecek çalışmalarda, bütün bir görüntüden polen taşıyan bal arılarının tespit edilmesi sayesinde sayı ve yoğunluk gibi bilgilere ulaşmak, diğer yandan, polen toplarının segmentasyonu ile daha geniş bir spektrumda "polen analizi" gerçekleştirmek mümkün olacaktır.

\section{Kaynakça}

Ankara Valiliği Gıda Tarım ve Hayvancılık İl Müdürlüğü. (2015). Polen. Ankara Valiliği Gıda Tarım ve Hayvancılık İl Müdürlüğü.

https://ankara.tarimorman.gov.tr/Belgeler/liftet/polen.pdf

Babic, Z., Pilipovic, R., Risojevic, V., \& Mirjanic, G. (2016). Pollen bearing honey bee detection in hive entrance video recorded by remote embedded system for pollination monitoring. ISPRS Annals of Photogrammetry, Remote Sensing and Spatial Information Sciences, III-7, 51-57.

Bağrıçık, N. (2017). Polinatör böcekler ve küresel tozlaşma krizi. Iğdır Üniversitesi Fen Bilimleri Enstitüsü Dergisi, 7(4), $37-41$.

Başdoğan, G., Sağdıç, O., Daştan, T., Acar, S., \& Düz, G. (2019). Farklı bölgelerden toplanan arı polenlerinin fizikokimyasal özellikleri ve şeker profillerinin belirlenmesi. Avrupa Bilim ve Teknoloji Dergisi, 15, 627-631.

Bozkurt, Z. (2020). Bal arılarında refah. Bahri Dağdaş Hayvancıllk Araştırma Dergisi, 8(2), 96-108.

Chen, C., Yang, E.-C., Jiang, J.-A., \& Lin, T.-T. (2012). An imaging system for monitoring the in-and-out activity of honey bees. Computers and Electronics in Agriculture, 89, $100-109$.

Chollet, F. (2017). Xception: Deep learning with depthwise separable convolutions. ArXiv:1610.02357 [Cs]. http://arxiv.org/abs/1610.02357

Cubuk, E. D., Zoph, B., Mane, D., Vasudevan, V., \& Le, Q. V. (2018). AutoAugment: Learning augmentation policies from data. ArXiv:1805.09501 [Cs, Stat]. http://arxiv.org/abs/1805.09501

Feurer, M., \& Hutter, F. (2019). Hyperparameter optimization. In F. Hutter, L. Kotthoff, \& J. Vanschoren (Eds.), Automated Machine Learning: Methods, Systems, Challenges (pp. 333). Springer International Publishing. https://doi.org/10.1007/978-3-030-05318-5_1

Hendrycks, D., Lee, K., \& Mazeika, M. (2019). Using pretraining can improve model robustness and uncertainty. ArXiv:1901.09960 [Cs, Stat]. http://arxiv.org/abs/1901.09960

Howard, A. G., Zhu, M., Chen, B., Kalenichenko, D., Wang, W., Weyand, T., Andreetto, M., \& Adam, H. (2017). MobileNets: Efficient convolutional neural networks for mobile vision applications. ArXiv:1704.04861 [Cs]. http://arxiv.org/abs/1704.04861

ImageNet. (2020). ImageNet. http://image-net.org/aboutoverview

Karaboga, D., \& Basturk, B. (2007). A powerful and efficient algorithm for numerical function optimization: Artificial bee colony (ABC) algorithm. Journal of Global Optimization, 39(3), 459-471.

Karpathy, A. (2018). Transfer Learning. http://cs231n.github.io/transfer-learning/

Keras. (2020). Keras documentation: Keras Applications. https://keras.io/api/applications/

Lu, J., Behbood, V., Hao, P., Zuo, H., Xue, S., \& Zhang, G. (2015). Transfer learning using computational intelligence: A survey. Knowledge-Based Systems, 80, 14-23. https://doi.org/10.1016/j.knosys.2015.01.010

Perez, L., \& Wang, J. (2017). The effectiveness of data augmentation in image classification using deep learning. ArXiv:1712.04621 [Cs]. http://arxiv.org/abs/1712.04621

Rodriguez, Ivan F., Megret, R., Acuna, E., Agosto-Rivera, J. L., \& Giray, T. (2018). Recognition of pollen-bearing bees from video using convolutional neural network. 2018 IEEE Winter Conference on Applications of Computer Vision (WACV), 314-322.

Rodriguez, Ivan Felipe. (2018). Pollen dataset. GitHub. https://github.com/piperod/PollenDataset

Sandler, M., Howard, A., Zhu, M., Zhmoginov, A., \& Chen, L.-C. (2019). MobileNetV2: Inverted residuals and linear bottlenecks. ArXiv:1801.04381 [Cs]. http://arxiv.org/abs/1801.04381

Sarıül, T. (2018). Arılar nasıl bal yapar? Balın yapısında hangi maddeler var? TÜBİTAK Bilim Genç. https://bilimgenc.tubitak.gov.tr/makale/arilar-nasil-balyapar-balin-yapisinda-hangi-maddeler-var 
Schönfelder, M. L., \& Bogner, F. X. (2017). Individual perception of bees: Between perceived danger and willingness to protect. PLOS ONE, 12(6), e0180168.

Selvaraju, R. R., Cogswell, M., Das, A., Vedantam, R., Parikh, D., \& Batra, D. (2017). Grad-CAM: Visual explanations from deep networks via gradient-based localization. 2017 IEEE International Conference on Computer Vision (ICCV), 618 626. https://doi.org/10.1109/ICCV.2017.74

Shen, D., Wu, G., \& Suk, H.-I. (2017). Deep learning in medical image analysis. Annual Review of Biomedical Engineering, 19(1), 221-248. https://doi.org/10.1146/annurev-bioeng071516-044442

Silici, S. (2014). Arı poleni ve arı ekmeği. Uludağ Arıcllık Dergisi, 14(2), 99-105.

Silici, S. (2020). Ekolojik dengenin odağındaki hayvan: Bal arısı. Anadolu Ajansı. https://www.aa.com.tr/tr/turkiye/ekolojikdengenin-odagindaki-hayvan-bal-arisi/1847545

Siralı, R., Uğur, A., \& Türkmen, M. (2011). Bal arılarının sebze üretimindeki rolü. Arıcılık Araştırma Dergisi, 6, 3-6.

Szegedy, C., Ioffe, S., Vanhoucke, V., \& Alemi, A. A. (2017). Inception-v4, Inception-ResNet and the impact of residual connections on learning. Thirty-First AAAI Conference on Artificial Intelligence (AAAI-17), 4278-4284.

Tu, G. J., Hansen, M. K., Kryger, P., \& Ahrendt, P. (2016). Automatic behaviour analysis system for honeybees using computer vision. Computers and Electronics in Agriculture, $122,10-18$.

Türkiye Arı Yetiştiricileri Merkez Birliği. (2016a). Polen. Türkiye Arı Yetiştiricileri Merkez Birliği. http://www.tab.org.tr/polen

Türkiye Arı Yetiştiricileri Merkez Birliği. (2016b). Polinasyon. Türkiye Arı Yetiştiricileri Merkez Birliği. http://www.tab.org.tr/polinasyon

Tüzün, A., \& Bilgili, G. (2013). Tarımsal ekosistemde arıların önemi. Biyoloji Bilimleri Araştırma Dergisi, 6(2), 91-95.

Yosinski, J., Clune, J., Bengio, Y., \& Lipson, H. (2014). How transferable are features in deep neural networks? Advances in Neural Information Processing Systems 27. Advances in Neural Information Processing Systems 27, Montreal, QC, Canada. http://papers.nips.cc/paper/5347-how-transferableare-features-in-deep-neural-networks.pdf 